\title{
NM23/NDPK proteins in transcription regulatory functions and chromatin modulation: emerging trends
}

\author{
Shalu Sharma ${ }^{1,2}$, Antara Sengupta ${ }^{1}$ and Shantanu Chowdhury ${ }^{1,2,3}$
}

NM23/NDPK proteins have been studied for their metastasis suppressor role but the molecular pathways involved in this process are not very vivid. Nucleotide binding and kinase activities of NM23 proteins implicated in anti-metastatic effects have been widely studied. In addition to these, transcriptional regulation adds another arm to the versatility of NM23 proteins that together with the other functions may contribute to better understanding of underlying mechanisms. In this review we discuss emerging reports describing the role of NM23 proteins in gene regulation and chromatin modulation in association with other factors or on their own.

Laboratory Investigation (2018) 98, 175-181; doi:10.1038/labinvest.2017.98; published online 30 October 2017

The metastasis suppressor gene $N M E / n m 23 / N D P K$ was discovered in 1988 by Steeg et al, ${ }^{1}$ from the analysis of murine melanoma K-1735 cells based on its differential expression with respect to metastatic potential. The first identified member of the $n m 23$ metastasis suppressor gene family has been extensively studied ever since. Later, in 1991 a close homolog of NM23-H1 that shared $>88 \%$ sequence identity was found and referred to as NM23-H2. ${ }^{2}$ Subsequently 10 other homologs of this family were discovered across several other species. ${ }^{3}$ nm 23 gene homologs are found in almost all organisms including eukaryotes, eubacteria as well as archaea, ${ }^{4}$ the only exception being the Mycoplasma taxon. ${ }^{5}$ NM23 are multifunctional, ubiquitously distributed hexameric histidine kinases that catalyze phosphate-transfer from nucleloside triposphates to diphosphates via a phosphohistidine intermediate following a ping-pong mechanism. ${ }^{6-10}$ They are involved in regulating several fundamental cellular processes such as cell proliferation, apoptosis, G-protein signaling, and DNA repair. ${ }^{11-13}$

Among the human members of the $n m 23$ gene family $n m 23-H 1$ and $n m 23-H 2$ are widely studied as metastasis suppressors and discussed in several reviews. ${ }^{14-17}$ The phylogenetic analysis of NM23 family members divided them into two distinct groups. ${ }^{3,12}$ Group I includes NM23-H1-H4 -enzymatically active proteins that are $58-88 \%$ identical, whereas group II includes proteins that are enzymatically inactive and more divergent, ie, with $22-44 \%$ identity. ${ }^{3,12}$
Members of the NM23 family are known to be involved in multiple DNA-associated functions including nucleotide binding, nucleoside triphosphate synthesis, cleavage of DNA strands through nuclease activity as well as transcription. ${ }^{12}$ The kinase-related activities of NM23 proteins including their role in metastasis suppression have been discussed in multiple reviews. ${ }^{6-11}$ Although studies about the role of NM23 in gene regulation and chromatin-associated changes are relatively more recent, this review will focus on these aspects.

\section{NDPK/NM23 PROTEINS: EVIDENCE SUPPORTING ROLE IN TRANSCRIPTION}

Several lines of evidence implicate the role of NM23 proteins in transcriptional regulation of gene expression. These include first, studies such as those substantiating nuclear localization of NM23 proteins, although they have been reported to lack any nuclear localization signal. ${ }^{18}$ Not only NM23-H1 and H2 the more frequently studied members of the NM23 family but also NM23-H4 was reported to localize in the nucleus. ${ }^{19}$ Several reports describe nuclear localization of NM23-H1 and NM23-H2 showing cell cycle-dependent transport of NM23$\mathrm{H} 1$ and $\mathrm{H} 2$ proteins from cytoplasm to the nucleus during interphase. ${ }^{18,20,21}$ In addition, Fujita et al ${ }^{19}$ also showed nuclear localization of NM23-H4, which was previously understood to be found mainly within mitochondria. Second, multiple reports describe binding of NM23-H1/H2 proteins to the nuclease-hypersensitive element (NHE) region within

\footnotetext{
${ }^{1}$ Genomics and Molecular Medicine Unit, CSIR-Institute of Genomics and Integrative Biology, New Delhi, India; ${ }^{2}$ Academy of Scientific and Innovative Research (AcSIR), Rafi Marg, New Delhi, India and ${ }^{3}$ G.N.R. Knowledge Centre for Genome Informatics, Institute of Genomics and Integrative Biology, CSIR, New Delhi, India

Correspondence: Dr S Chowdhury, PhD, Genomics and Molecular Medicine Unit, CSIR-Institute of Genomics and Integrative Biology, Sukhdev Vihar, Mathura Road, New Delhi 110025, India.
}

E-mail: shantanuc@igib.res.in

Received 20 May 2017; revised 23 June 2017; accepted 30 June 2017 
Table 1 NM23/NDPK proteins carry characteristics of conventional transcription factors

\begin{tabular}{|c|c|}
\hline $\mathrm{NM} 23-\mathrm{H} 1$ and $\mathrm{H} 2$ & NM23-H1 and NM23-H2 localize to nucleus mainly in interphase ${ }^{18,20,21}$ \\
\hline NM23-H4 & Increased nuclear localization was demonstrated on SIRT1 mediated acetylation of NM23-H4 $4^{19}$ \\
\hline \multicolumn{2}{|c|}{ NM23 proteins with DNA-binding potential } \\
\hline $\mathrm{NM} 23-\mathrm{H} 2$ & NM23-H2 binds c-myc promoter purine-rich sequence GGGTGGG22,23 \\
\hline $\mathrm{NM} 23-\mathrm{H} 2$ and NM23-H1 & Involvement of Arg34, Asn-69, and Lys-135 residues in DNA binding 25 \\
\hline $\mathrm{NM} 23-\mathrm{H} 1$ and $\mathrm{NM} 23-\mathrm{H} 2$ & Both the isoforms demonstrated to interact with PDGF-A promoter ${ }^{24}$ \\
\hline $\mathrm{NM} 23-\mathrm{H} 1$ and $\mathrm{NM} 23-\mathrm{H} 2$ & Occupancy on several gene promoters CCR5, CD11b, p53, WT1, ING166 \\
\hline $\mathrm{NM} 23-\mathrm{H} 2$ & Interaction with G-quadruplex DNA in c-myc promoter ${ }^{48}$ \\
\hline $\mathrm{NM} 23-\mathrm{H} 2$ and $\mathrm{NM} 23-\mathrm{H} 1$ & DNA binding with telomeric ssDNA repeats 26,27 \\
\hline Maize ZmNDPK1 & Interaction with G-quadruplex DNA ${ }^{54}$ \\
\hline \multicolumn{2}{|c|}{ NM23 proteins interact with other regulatory proteins } \\
\hline \multirow[t]{2}{*}{ NM23-H1 } & Interaction with EBNA3C and regulation of MMP-9,,$^{37} \mathrm{COX}{ }_{1}^{38}$ alpha $V$ integrin, ${ }^{39}$ Necdin; $; 0$ interaction of mouse NM $23 \beta$ with YB-1 \\
\hline & inhibits gelatinas A expression 33 \\
\hline $\mathrm{NM} 23-\mathrm{H} 2$ & Interaction with $E R \beta$ and activation of downstream genes $31,32,56$ \\
\hline NM23-H1 & $\begin{array}{l}\text { Interaction with STRAP and repression of TGF } \beta \text { downstream signaling; }{ }^{41,42} \text { interaction with ERa and repression downstream } \\
\text { genes }^{29}\end{array}$ \\
\hline \multirow[t]{2}{*}{$\mathrm{NM} 23-\mathrm{H} 2$} & Interaction with CNBP activates c-myc; $; 0$ interaction with APP regulates Alzheimer's disease progression; ${ }^{57}$ NME2-PIWIL2 \\
\hline & interaction upregulates $c-m y c^{55}$ \\
\hline
\end{tabular}

the promoter of the oncogene $c-m y c$ and $p d g f-a$, resulting in transcriptional activation of $c-m y c$ and repression of $p d g f-a^{22-24}$ Consequently, the Arg34, Asn-69, and Lys-135 amino-acid residues were reported to mediate NM23-H1 and NM23-H2 DNA binding. ${ }^{25}$ Interestingly, apart from binding at gene promoters interaction with telomeric DNA was also noted. ${ }^{26,27}$ Third, apart from direct DNA interactions, NM23 proteins were also reported to regulate expression of multiple genes through other transcription factors and regulatory proteins. For example, NM23-H1 was reported to associate with the Epstein-Barr virus nuclear antigen $3 \mathrm{C}$ EBNA3C, estrogen receptor alpha $(\mathrm{ER} \alpha)$ and other factors ${ }^{28,29}$ NM23-H2 was shown to associate with several factors including the cellular nucleic acid binding protein such as $\mathrm{CNBP},{ }^{30}$ estrogen receptor beta $(\mathrm{ER} \beta)^{31,32}$ thereby activating $c$ - $m y c$ expression (these are discussed in detail below). Table 1 summarizes these aspects for ready reference.

\section{NM23-H1 AND TRANSCRIPTION REGULATION THROUGH DNA BINDING}

The first report of transcription regulatory role was from Kaetzel's group in 2002 demonstrating NM23-H1 mediated transcriptional repression of the oncogene $p d g f-a$ in HeLa cells. ${ }^{24} \mathrm{NM} 23-\mathrm{H} 1$ was shown to recognize both, a 5' distal S1 nuclease-hypersensitive silencer element and a proximal regulatory $\mathrm{NHE}$ of the $p d g f-a$ promoter. Interestingly, nuclease activity of NM23-H1 within the promoter of $p d g f-$ $a$ was shown to cleave the 3 ' end of both the pyrimindine- and purine-rich strands independent of single or double stranded conformation. $^{24}$ In 2002, NM23 $\beta$ (rat homolog of NM23-H1) was shown to regulate gelatinase $A$ by binding with the GGGTTT-repetitive sequence within the $40 \mathrm{bp}$ enhancer response element 1 (RE-1) of gelatinase A. Overexpression of $n m 23 \beta$ in glomerular mesangial cells was found to outcompete the Y-box protein-1 from the RE-1 binding site resulting in repression of gelatinase $A .{ }^{33}$ Recently, NM23-H1 was reported to induce expression of the extracellular matrix protein fibronectin mRNA and protein in M14 and 1205LU melanoma cell lines. These results were further confirmed in clinical biopsies of normal skin, benign nevi and also in primary melanomas. ${ }^{34}$

\section{GENE REGULATION BY NM23-H1 IN COLLABORATION WITH OTHER FACTORS}

A substantial body of literature suggests regulation by NM23$\mathrm{H} 1$ that is executed through interaction with other proteins or regulatory factors. Interaction of NM23-H1 with the EpsteinBarr virus protein nuclear antigen 3C (EBNA3C) showed increased NM23-H1 nuclear localization and altered NM23$\mathrm{H} 1$ transcriptional activities that influenced both cellular and viral gene expression. Interestingly, this interaction negatively impacts the function of NM23-H1 in suppressing migration 
of breast carcinoma and Burkitt's lymphoma cells in vitro. ${ }^{28,35,36}$ In 2005, Kuppers et $a^{37}$ further showed NM23$\mathrm{H} 1$ interaction with EBNA3C resulted in upregulation of matrix metalloproteinase 9 (MMP-9) expression through association with Ap1 and NFKB-binding sites on MMP-9 promoter. This interaction reversed the anti-migratory effect of NM23-H1. NM23-H1 and EBNA3C cooperation was also noted to transcriptionally upregulate cyclooxygenase 2 (COX-2) expression by co-binding to target sequences of transcription factors $\mathrm{NF} \kappa \mathrm{B}$ and $\mathrm{CRE}$ in the $\mathrm{COX}-2$ promoter. NM23-H1 upregulated COX2, whereas EBNA3C alone had no effect on $C O X-2$ expression but contributed to increased COX2 expression when coexpressed with NM23-H1. ${ }^{38}$

In addition to these, reports also showed that NM23-H1 and EBNA3C regulate alpha $\mathrm{V}$ integrin expression independently as well as synergistically by binding different transcription factors. EBNA3C binding to the transcription factor Sp1 upregulates alpha V integrin. On the other hand, NM23-H1 binding to GATA-1 resulted in repression of alpha $\mathrm{V}$ integrin. Again, NM23-H1 and EBNA3C when coexpressed negated the repression of alpha $\mathrm{V}$ integrin expression mediated by NM23-H1. ${ }^{39}$ Additional work from the same group showed NM23-H1-EBNA3C interaction to be important for transcriptional suppression of the cellular regulatory factor Necdin. Interestingly, Necdin downregulation rescued downstream suppression of the vascular endothelial growth factor (VEGF) promoter and thereby abrogated antiangiogenic effects. ${ }^{40}$

Protein-protein interactions through NM23-H1 and its impact on gene regulation were also evident from association of NM23-H1 with $\mathrm{ER} \alpha$, which enhanced binding of $\mathrm{ER} \alpha$ with the estrogen response element (ERE). This study demonstrated that NM23-H1 silencing in U2 osteosarcoma and MDA-MB231 breast cancer cells resulted in downregulation of an ERE-harboring reporter plasmid, supporting transcription regulation of ERE-harboring progesterone receptor, $B c l 2$, cyclin-D1 and cathepsin through NM23-H1 However, other ERE-containing genes like pS2 remained unaltered by NM23H1 levels. ${ }^{29}$

Interaction of NM23-H1 with the serine threonine kinase receptor associated protein (STRAP) was reported to transcriptionally repress PAI-1, p21 and SMAD7 together with activation of CDK4 and cyclin-D1. These together were shown to repress the downstream TGF $\beta$ signaling. ${ }^{41}$ The same group also reported NM23-H1-STRAP association, following genotoxic stress, with p53 using cystein residues in the central DNA-binding domain (DBD) of p53. Through this interaction NM23-H1-STRAP was found to regulate p53-mediated transcription of apoptosis and cell cycle-related proteins ${ }^{42}$

\section{NM23-H1-ROLE IN GLOBAL GENE REGULATION}

In addition to studies showing involvement of NM23-H1 in gene regulation either directly or in association with other factors several global studies revealed differential mRNA expression following altered NM23-H1 expression.
Microarray analysis performed on oral squamous cell carcinoma cells CAL27 after subjecting them to NM23-H1 overexpression observed 241 genes with change of more than or equal to twofold, 103 of these genes were downregulated, whereas 138 showed upregulation. ${ }^{43}$ The altered genes were primarily related to cell adhesion, invasion, and metastasis including TGF $\beta$ signaling. In another study on transfection of breast cancer MDA-MB-435 cells with nm23-H1, 197 genes were found to be significantly upregulated, whereas the expression of 1961 genes were downregulated. ${ }^{44}$ Functional significance of the altered genes showed them to cluster into six categories namely, invasion and metastasis, apoptosis and senescence, signal transduction and transcription factors, cell cycle and repair, adhesion, and angiogenesis.

Horak et $a l^{45}$ compared the expression profiles following NM23-H1 overexpressing with cells overexpressing NM23H1 mutants P96S and S120G that are incapable of inhibiting motility and invasion in breast cancer cells. This study reported nine genes (MET, FZD1, PTN, SMO L1CAM, NETO2, CTGF, MMP-2, and EDG2) downregulated by the wild-type NM23-H1 that remained unaltered in case of NM23-H1 mutants. A later transcriptome analysis in L9981 lung cancer cells showed similar observations. ${ }^{46}$ L9981-nm23H1 stable cells characteristically exhibited lower cell proliferation, increased apoptosis and a dramatic loss of tumor cell metastasis. This study emphasized the finding that genes like E-cadherin, b-catenin and TIMP-1 were upregulated, whereas $M M P-2, C D 44 v 6$, and VEGF were repressed on NM23-H1 overexpression, suggesting altered expression of these genes to be significant in the anti-metastatic function of NM23-H1.

\section{DNA BINDING BY NM23-H2 AND TRANSCRIPTIONAL REGULATION OF GENE EXPRESSION}

Transcriptional activation of the $c-m y c$ oncogene by NM23$\mathrm{H} 2$ was shown in human as well as murine cells, in cervical, lung carcinoma, and Burkitt lymphoma by multiple research groups. ${ }^{16,22,47,48}$ Furthermore, it was found that NM23-H2 associates with the $c-m y c$ promoter NHE, constituting an asymmetric repetitive sequence that is cytosine-rich in one strand and guanine-rich in the other-an arrangement conducive to formation of specific DNA secondary structures called G-quadruplexes. ${ }^{23,49-51}$ Later, it was shown that NM23$\mathrm{H} 2$ interacts with the $c-m y c$ promoter in a manner that was dependent on formation of the G-quadruplex structure. ${ }^{48}$ Despite these, reports have cast doubt on transcriptional activity of NM23-H2 because of non-specific binding to single-stranded purine-rich sequence. ${ }^{52,53}$ On the other hand, it is possible that NM23-H2 association to DNA depends on the structure adopted by such sequences rather than mere sequence. In 2015, in maize nucleoside diphosphate kinase1 (ZmNDPK1) the first plant G-quadruplexbinding protein was reported. It is a close homologue of NM23-H2, which was shown to bind folded G-quadruplex structures with higher affinity as compared to unfolded 
G-rich DNA. The G-quadruplex-binding activity of ZmNDPK1 was demonstrated to be independent of its nucleotide binding and kinase activities. ${ }^{54}$

\section{GENE REGULATION BY NM23-H2 IN ASSOCIATION WITH OTHER FACTORS}

Recently, a NM23-H2-interacting protein was reported in relation to $c-m y c$ regulation, which supported earlier studies of NM23-H2-G-quadruplex binding in the $c$-myc promoter. Piwi-like RNA-mediated gene silencing 2, PIWIL2 interaction with NM23-H2 was found to upregulate $c-m y c$ expression by facilitating the association of NM23-H2 with the G-quadruplex motif. ${ }^{55}$ In addition to these, CNBP was shown to interact with $\mathrm{NM} 23-\mathrm{H} 2$ and regulate $c-m y c$ expression. It was further demonstrated that CNBP binds to the G-quadruplex structure formed in the NHE region within the $c-M Y C$ promoter and while CNBP repressed c-MYC, CNBPNM23-H2 interaction resulted in upregulation of $c-M Y C$ expression. ${ }^{30}$

As noted for NM23-H1, NM23-H2 also mediated negative regulation of $p d g f-a$ transcription by interacting with its silencer sequence (5'-S1 nuclease-hypersensitive site) along with basal NHE. On transient transfection of NM23-H2 negative regulation of the $p d g f-a$ basal promoter was found in HepG2 cells. ${ }^{24}$ In addition to these, Rayner et al ${ }^{31}$ demonstrated association of $\mathrm{NM} 23-\mathrm{H} 2$ with the $\mathrm{ER} \beta .^{32}$ Interestingly, in contrast to NM23-H1, which associates with estrogen receptor alpha and functions as a repressor in a estrogen dependent manner, NM23-H2 was found to activate gene expression. ${ }^{31,32,56}$

In 2013, regulation of the alzheimer associated amyloid- $\beta$ peptide $(A P P)$ was found to be through interaction of NM23$\mathrm{H} 2$ to the proximal regulatory element (PRE) within the APP promoter. Presence of the 30 nucleotide PRE sequence was reported to make $A P P$ regulation vulnerable to epigenetic modifications. This report further implicated an increased risk of Alzheimer's disease on any interference with NM23$\mathrm{H} 2$ 's role in regulation of $A P P .{ }^{57}$

\section{GENOMIC STUDIES ON NM23-H2-MEDIATED GENE REGULATION}

In 2014, gene expression profiling along with promoter occupancy of NM23-H2 in lung carcinoma A549 cells was reported. ${ }^{58}$ Authors found occupancy of NM23-H2 within promoters of 346 genes related to focal adhesion, nucleosome remodeling, transcriptional regulation, apoptosis, Notch signaling pathway, p53, and Wnt signaling pathways. Of these, 64 gene targets also showed altered expression, either up or downregulation, on changing NM23-H2 levels in the cell. Several targets, for example, adenomatous polyposis coli $(A P C)$, Rho-related GTP-binding protein $\mathrm{B}(\mathrm{RHO} B)$ and connective tissue growth factor (CTGF) were found to be under direct regulation of NM23-H2. The study thereafter focused on NM23-H2-mediated transcriptional repression of the focal adhesion factor vinculin (VCL). NM23-H2 was shown to bind a 12-mer motif located 262 bases upstream of vinculin transcription start site. ${ }^{58}$

In a later more extensive study, genome-wide chromatinimmunoprecipitation followed by sequencing (ChIP-seq) was performed in A549 cells and NM23-H2 target sites were checked before and after induction of nm23-H2. ${ }^{59}$ A 12-mer consensus motif was identified for NM23-H2 binding, which was present in $>70 \%$ of the ChIP-seq peaks - a motif that was similar to the one reported by Postel et al within the $c$ $m y c$ promoter NHE several years earlier. ${ }^{23,58}$ This further revealed 2005 and 11017 peaks in endogenous and induced states respectively. On analyzing the altered gene expression profile 1679 genes were found to be differentially expressed in NM23-H2 altered conditions, 781 genes were upregulated, whereas 898 were downregulated. Of these 1679 gene targets, 1235 genes were found to have at-least one NM23-H2binding site within $10 \mathrm{~kb}$ of the transcription start site. ${ }^{59}$

A study that described genes differentially expressed in drug resistance cancer cells implicated NM23-H2 as a factor that altered expression of several well known genes involved in epithelial to mesenchymal transition. ${ }^{60}$ Based on this analysis it was tested and found that NM23-H2 repressed several mesenchymal cell markers (such as SNAI2, VIM, FN1, TIMP-1, ITGA5) while inducing expression of epithelial cell markers (OCLN, CDH1, DSP, PPDE2), thereby promoting mesenchymal to epithelial transition of breast cancer cells (MDA-MB-231). Furthermore, the study reported NM23-H2 levels to be important for preventing drug resistance in cancer cells. Overall, this also supported function of $\mathrm{NM} 23-\mathrm{H} 2$ as a metastasis suppressor. ${ }^{60}$

\section{NM23-H1 AND NM23-H2-MEDIATED CHROMATIN LEVEL CHANGES}

Interaction of NM23-H1 with the chromatin remodeling SET complex was reported in 2003 by Fan et al. ${ }^{61}$ The SET complex is a multimeric $270-420 \mathrm{KDa}$ complex, comprising HMGA, SET, Ape-1, and pp32, generally linked to the chromatin-associated processes of nucleosome assembly, replication, and DNA repair. ${ }^{61}$ On activation by granzyme A, NM23-H1 as a part of this complex was shown to induce DNase activity thereby inducing cellular apoptosis through chromatin degradation. ${ }^{61}$ In another study, both NM23-H1 and NM23-H2 were found to be part of a multi-component OCA-S (Oct-1 co-activator complex in S phase) complex in transcriptional activation of the histone $2 \mathrm{~B}$ gene in a $\mathrm{S}$ phasedependent manner. ${ }^{62}$ Although both NM23-H1 and NM23$\mathrm{H} 2$ were found to have occupancy on histone $2 \mathrm{~B}$ gene promoter, their exact role within OCA-S was not clear. This further implicated the significance of NM23 proteins in chromatin modification through regulation of a core histone protein.

More evidence supporting involvement of NM23 in chromatin remodeling was reported in 2014. In a genomewide ChIP-seq study, NM23-H2 was used as a candidate for testing whether transcription factor binding on target gene 
promoters influence nucleosome occupancy in its vicinity. ${ }^{59}$ Using lung cancer A549 cells, authors showed that on induction of NM23-H2, 70\% of the putative NM23-H2 binding sites earlier occupied by nucleosomes became nucleosome-free. Perhaps more importantly, it was also shown that these newly vacated sites were occupied by NM23$\mathrm{H} 2$, in the induced cells, resulting in altered expression of the target gene. ${ }^{59}$

In another study, a yeast two-hybrid screen found NDPK$\mathrm{D}$ (NM23-H4) associates with the $\mathrm{NAD}^{+}$dependent histone deactylase SIRT1. Here it was also shown that deacetylation by SIRT1 enhances the nuclear localization of NM23-H4. Since no evidence of any specific intra-nuclear functions of NM23-H4 has been revealed as yet it would be interesting to explore its role, if any, in gene regulation particularly due to its interaction with the nucleosome remodeler SIRT1. ${ }^{19}$

\section{TRANSACTIVATION DOMAIN IN NM23 PROTEINS: DIFFERING VIEWS}

In the light of transcriptional roles attributed to NM23 proteins, particularly NM23-H1 and $\mathrm{H} 2$, the differing views on whether they harbor transactivation domain(s) is of interest. NM23-H2 was first implicated in $c$-myc transactivation in 1995, but a distinct transactivator domain was not defined. $^{22}$ In 1997, presence of a typical transactivation domain was negated by Michelloti et al, ${ }^{63}$ when following reporter assays that fused a DBD with wild-type NM23-H2, authors did not observe any transactivation. In the following year, Chae et al ${ }^{64}$ reported presence of transactivation domain from studies where human nm23-H1 gene constructs were transfected in yeast. They co-transfected a fusion protein containing GAL4/LEXA DBD with a truncated versions of NM23-H1 and noted that the $C$-terminal residues of NM23 displayed clear transactivation potential, whereas no transactivation was observed through the $N$-terminal residues. Presence of a C-terminal transactivation domain was further substantiated later when transactivation activity of $C$-terminal residues of NM23-H1 (amino-acid 109-152) was found in yeast, HeLa, and COS cells. ${ }^{65}$ Interestingly it was noted that further extension of the domain (including amino acids from 58-152) lead to a loss of transactivation. Authors also tested the role specific mutants-C-terminal residues such as P96S, S120G/S120A (known to inhibit anti-metastatic effect of wildtype NM23-H1) and H118F (NDP Kinase mutant of NM23$\mathrm{H} 1$ ). Interestingly, only $\mathrm{H} 118 \mathrm{~F}$ showed reduction of transactivation activity suggesting a link between NDP kinase activity and transactivation potential NM23-H1. In another study, reporter assays in $293 \mathrm{~T}$ cells using NM23-H1 fused to Gal4 DBD authors found increase in reporter expression. ${ }^{28}$

\section{EMERGING TRENDS AND FUTURE PERSPECTIVE}

Research on regulation of gene expression by NM23 proteins themselves or in collaboration with other interacting partners was primarily discussed here. This, in addition to, the emerging work on involvement of NM23 in chromatin-related processes projects interesting line of work that has received relatively less attention. Also, several genome-wide studies have revealed the global impact of NM23-H1/H2 on a wide array of cellular processes including cell development, differentiation, and proliferation.

We particularly take note of the work that may link the inherent NDP kinase activity of NM23 to its role in gene expression based on the study that found loss of transactivation potential in the mutant NM23-H1 (H118F) devoid of kinase activity. ${ }^{65}$ Another interesting theme that may open up new avenues comes from the implicated involvement of NM23-H2 in modulating the state of regulatory chromatin through nucleosome repositioning within gene promoter. ${ }^{60}$ Based on these, future work on the influence of the NDP kinase activity in chromatin modifications, and mechanisms of how this impacts global gene regulation could be of much interest and impact.

\section{ACKNOWLEDGMENTS}

This work was supported by the Wellcome Trust/DBT India Alliance Fellowship [grant number 500127/Z/09/Z] awarded to SC. Authors acknowledge all Chowdhury-Lab members for their support and critical appreciation. SC is a Senior Fellow of the Wellcome Trust/DBT India Alliance.

\section{DISCLOSURE/CONFLICT OF INTEREST}

The authors declare no conflict of interest.

1. Steeg PS, Bevilacqua G, Kopper L, et al. Evidence for a novel gene associated with low tumor metastatic potential. J Natl Cancer Inst 1988;80:200-204.

2. Stahl JA, Leone A, Rosengard AM, et al. Identification of a second human nm23 gene, nm23-H2. Cancer Res 1991;51:445-449.

3. Desvignes T, Pontarotti P, Fauvel C, et al. Nme protein family evolutionary history, a vertebrate perspective. BMC Evol Biol 2009;9: 256.

4. Bilitou A, Watson J, Gartner A, et al. The NM23 family in development. Mol Cell Biochem 2009;329:17-33.

5. Fraser CM, Gocayne JD, White O, et al. The minimal gene complement of Mycoplasma genitalium. Science 1995;270:397-403.

6. Engel $M$, Véron $M$, Theisinger $B$, et al. A novel serine/threonine-specific protein phosphotransferase activity of Nm23/nucleosidediphosphate kinase. Eur J Biochem 1995;234:200-207.

7. Lacombe ML, Milon L, Munier A, et al. The human Nm23/nucleoside diphosphate kinases. J Bioenerg Biomembr 2000;32:247-258.

8. Roymans D, Willems $\mathrm{R}$, Van Blockstaele DR, et al. Nucleoside diphosphate kinase (NDPK/NM23) and the waltz with multiple partners: possible consequences in tumor metastasis. Clin Exp Metastasis 2002;19:465-476.

9. Wagner PD, Steeg PS, Vu ND. Two-component kinase-like activity of nm23 correlates with its motility-suppressing activity. Proc Natl Acad Sci USA 1997;94:9000-9005.

10. Attwood PV, Wieland T. Nucleoside diphosphate kinase as protein histidine kinase. Naunyn Schmiedebergs Arch Pharmacol 2015;388: 153-160.

11. Mehta A, Orchard S. Nucleoside diphosphate kinase (NDPK, NM23, AWD): recent regulatory advances in endocytosis, metastasis, psoriasis, insulin release, fetal erythroid lineage and heart failure; translational medicine exemplified. Mol Cell Biochem 2009;329:3-15.

12. Boissan $M$, Dabernat $S$, Peuchant $E$, et al. The mammalian Nm23/NDPK family: from metastasis control to cilia movement. Mol Cell Biochem 2009;329:51-62.

13. Hippe H-J, Wolf NM, Abu-Taha I, et al. The interaction of nucleoside diphosphate kinase $B$ with $\mathrm{G}$ dimers controls heterotrimeric $\mathrm{G}$ protein function. Proc Natl Acad Sci 2009;106:16269-16274. 
14. Hartsough MT, Steeg PS. Nm23/nucleoside diphosphate kinase in human cancers. J Bioenerg Biomembr 2000;32:301-308.

15. Steeg PS, Horak CE, Miller KD. Clinical-translational approaches to the Nm23-H1 metastasis suppressor. Clin Cancer Res Off J Am Assoc Cancer Res 2008;14:5006-5012.

16. Lee $\mathrm{JH}$, Marshall J-C, Steeg PS, et al. Altered gene and protein expression by $\mathrm{Nm} 23-\mathrm{H} 1$ in metastasis suppression. Mol Cell Biochem 2009;329:141-148.

17. Thakur RK, Yadav VK, Kumar P, et al. Mechanisms of non-metastatic 2 (NME2)-mediated control of metastasis across tumor types. Naunyn Schmiedebergs Arch Pharmacol 2011;384:397-406.

18. Bosnar MH, Bago R, Ćetković H. Subcellular localization of Nm23/NDPK $A$ and $B$ isoforms: a reflection of their biological function? Mol Cell Biochem 2009;329:63-71.

19. Fujita Y, Fujiwara K, Zenitani S, et al. Acetylation of NDPK-D regulates its subcellular localization and cell survival. PloS ONE 2015;10: e0139616.

20. Kraeft SK, Traincart F, Mesnildrey S, et al. Nuclear localization of nucleoside diphosphate kinase type B (nm23-H2) in cultured cells. Exp Cell Res 1996;227:63-69.

21. Bosnar MH, De Gunzburg J, Bago R, et al. Subcellular localization of $A$ and B Nm23/NDPK subunits. Exp Cell Res 2004;298:275-284.

22. Berberich SJ, Postel EH. PuF/NM23-H2/NDPK-B transactivates a human c-myc promoter-CAT gene via a functional nuclease hypersensitive element. Oncogene 1995;10:2343-2347.

23. Postel EH, Berberich SJ, Rooney JW, et al. Human NM23/nucleoside diphosphate kinase regulates gene expression through DNA binding to nuclease-hypersensitive transcriptional elements. J Bioenerg Biomembr 2000;32:277-284.

24. Ma D, Xing $Z$, Liu $B$, et al. NM23-H1 and NM23-H2 repress transcriptional activities of nuclease-hypersensitive elements in the platelet-derived growth factor-A promoter. J Biol Chem 2002;277: 1560-1567.

25. Postel EH, Weiss VH, Beneken J, et al. Mutational analysis of NM23-H2/ NDP kinase identifies the structural domains critical to recognition of a c-myc regulatory element. Proc Natl Acad Sci USA 1996;93: 6892-6897.

26. Nosaka $K$, Kawahara $M$, Masuda $M$, et al. Association of nucleoside diphosphate kinase $\mathrm{nm} 23-\mathrm{H} 2$ with human telomeres. Biochem Biophys Res Commun 1998;243:342-348.

27. Kar A, Saha D, Purohit G, et al. Metastases suppressor NME2 associates with telomere ends and telomerase and reduces telomerase activity within cells. Nucleic Acids Res 2012;40:2554-2565.

28. Subramanian C, Robertson ES. The metastatic suppressor $\mathrm{Nm} 23-\mathrm{H} 1$ interacts with EBNA3C at sequences located between the glutamineand proline-rich domains and can cooperate in activation of transcription. J Virol 2002;76:8702-8709.

29. Curtis CD, Likhite VS, McLeod IX, et al. Interaction of the tumor meastasis suppressor nonmetastatic protein 23 homologue $\mathrm{H} 1$ and estrogen receptor alters estrogen-responsive gene expression. Cancer Res 2007;67:10600-10607.

30. Chen S, Su L, Qiu J, et al. Mechanistic studies for the role of cellular nucleic-acid-binding protein (CNBP) in regulation of c-myc transcription. Biochim Biophys Acta 2013;1830:4769-4777.

31. Rayner K, Chen Y-X, Hibbert B, et al. Discovery of NM23-H2 as an estrogen receptor $\beta$-associated protein: role in estrogen-induced gene transcription and cell migration. J Steroid Biochem Mol Biol 2008;108: 72-81.

32. Rayner K, Chen Y-X, Hibbert B, et al. NM23-H2, an estrogen receptor beta-associated protein, shows diminished expression with progression of atherosclerosis. AJP Regul Integr Comp Physiol 2006;292: R743-R750.

33. Cheng S, Alfonso-Jaume MA, Mertens PR, et al. Tumour metastasis suppressor, nm23-beta, inhibits gelatinase $A$ transcription by interference with transactivator Y-box protein-1 (YB-1). Biochem J 2002;366: 807-816.

34. Novak M, Leonard MK, Yang $\mathrm{XH}$, et al. Metastasis suppressor NME1 regulates melanoma cell morphology, self-adhesion and motility via induction of fibronectin expression. Exp Dermatol 2015;24:455-461.

35. Subramanian C, Cotter MA, Robertson ES. Epstein-Barr virus nuclear protein EBNA-3C interacts with the human metastatic suppressor Nm23-H1: a molecular link to cancer metastasis. Nat Med 2001; 350-355.
36. Murakami M, Kaul R, Kumar $\mathrm{P}$, et al. Nucleoside diphosphate kinase/ $\mathrm{Nm} 23$ and Epstein-Barr virus. Mol Cell Biochem 2009;329:131-139.

37. Kuppers DA, Lan K, Knight JS, et al. Regulation of matrix metalloproteinase 9 expression by Epstein-Barr virus nuclear antigen $3 \mathrm{C}$ and the suppressor of metastasis Nm23-H1. J Virol 2005;79: 9714-9724.

38. Kaul R, Verma SC, Murakami M, et al. Epstein-Barr virus protein can upregulate cyclo-oxygenase-2 expression through association with the suppressor of metastasis Nm23-H1. J Virol 2006;80:1321-1331.

39. Choudhuri $\mathrm{T}$, Verma SC, Lan $\mathrm{K}$, et al. Expression of alpha V integrin is modulated by Epstein-Barr virus nuclear antigen $3 \mathrm{C}$ and the metastasis suppressor $\mathrm{Nm} 23-\mathrm{H} 1$ through interaction with the GATA-1 and Sp1 transcription factors. Virology 2006;351:58-72.

40. Kaul R, Murakami M, Lan K, et al. EBNA3C can modulate the activities of the transcription factor Necdin in association with metastasis suppressor protein Nm23-H1. J Virol 2009;83:4871-4883.

41. Seong $\mathrm{H}-\mathrm{A}$, Jung $\mathrm{H}, \mathrm{Ha} H$. NM23-H1 tumor suppressor physically interacts with serine-threonine kinase receptor-associated protein, a transforming growth factor-beta (TGF-beta) receptor-interacting protein, and negatively regulates TGF-beta signaling. J Biol Chem 2007;282:12075-12096.

42. Jung $\mathrm{H}$, Seong $\mathrm{H}-\mathrm{A}, \mathrm{Ha} \mathrm{H}$. NM23-H1 tumor suppressor and its interacting partner STRAP activate p53 function. J Biol Chem 2007;282: 35293-35307.

43. Bosnar MH, Bago R, Gall-Trošelj K, et al. Downstream targets of Nm23H1: gene expression profiling of CAL 27 cells using DNA microarray. Mol Carcinog 2006;45:627-633.

44. Zhao $\mathrm{H}$, Jhanwar-Uniyal M, Datta PK, et al. Expression profile of genes associated with antimetastatic gene:nm23-mediated metastasis inhibition in breast carcinoma cells. Int J Cancer 2004;109:65-70.

45. Horak $\mathrm{CE}$, Lee JH, Elkahloun AG, et al. Nm23-H1suppresses tumor cell motility by downregulating the lysophosphatidic acid receptor EDG2. Cancer Res 2007;67:7238-7246.

46. Cai C, Ye S, Zhu W, et al. [Study on invasion and metastasis-associated genes of lung cancer related with NM23-H1 gene]. Sichuan Da Xue Xue Bao Yi Xue Ban 2010;41:941-945.

47. Ji $\mathrm{L}$, Arcinas $\mathrm{M}$, Boxer $\mathrm{LM}$. The transcription factor, $\mathrm{Nm} 23 \mathrm{H} 2$, binds to and activates the translocated c-myc allele in Burkitt's lymphoma. J Biol Chem 1995:270:13392-13398.

48. Thakur RK, Kumar P, Halder K, et al. Metastases suppressor NM23-H2 interaction with G-quadruplex DNA within c-MYC promoter nuclease hypersensitive element induces c-MYC expression. Nucleic Acids Res 2009:37:172-183.

49. Boles TC, Hogan ME. DNA structure equilibria in the human c-myc gene. Biochemistry (Mosc) 1987;26:367-376.

50. Simonsson T, Pribylova M, Vorlickova M. A nuclease hypersensitive element in the human c-myc promoter adopts several distinct i-tetraplex structures. Biochem Biophys Res Commun 2000;278: 158-166.

51. Siddiqui-Jain A, Grand $\mathrm{CL}$, Bearss $\mathrm{DJ}$, et al. Direct evidence for a G-quadruplex in a promoter region and its targeting with a small molecule to repress c-MYC transcription. Proc Natl Acad Sci USA 2002;99:11593-11598.

52. Hildebrandt $M$, Lacombe ML, Mesnildrey S, et al. A human NDP-kinase $B$ specifically binds single-stranded poly-pyrimidine sequences. Nucleic Acids Res 1995;23:3858-3864.

53. Agou F, Raveh S, Mesnildrey $S$, et al. Single strand DNA specificity analysis of human nucleoside diphosphate kinase B. J Biol Chem 1999:274:19630-19638.

54. Kopylov M, Bass HW, Stroupe ME. The maize (Zea mays L.) nucleoside diphosphate kinase1 (ZmNDPK1) gene encodes a human NM23-H2 homologue that binds and stabilizes G-quadruplex DNA. Biochemistry (Mosc) 2015;54:1743-1757.

55. Yao Y, Li C, Zhou X, et al. PIWIL2 induces c-Myc expression by interacting with NME2 and regulates c-Myc-mediated tumor cell proliferation. Oncotarget 2014;5:8466-8477.

56. Hartman J, Edvardsson K, Lindberg K, et al. Tumor repressive functions of estrogen receptor in SW480 colon cancer cells. Cancer Res 2009;69: 6100-6106.

57. Lahiri DK, Maloney B, Rogers JT, et al. PuF, an antimetastatic and developmental signaling protein, interacts with the Alzheimer's amyloid- $\beta$ precursor protein via a tissue-specific proximal regulatory element (PRE). BMC Genomics 2013;14:68. 
58. Thakur RK, Yadav VK, Kumar A, et al. Non-metastatic 2 (NME2)mediated suppression of lung cancer metastasis involves transcriptional regulation of key cell adhesion factor vinculin. Nucleic Acids Res 2014;42:11589-11600.

59. Yadav VK, Thakur RK, Eckloff B, et al. Promoter-proximal transcription factor binding is transcriptionally active when coupled with nucleosome repositioning in immediate vicinity. Nucleic Acids Res 2014;42: 9602-9611.

60. Yadav VK, Kumar A, Mann A, et al. Engineered reversal of drug resistance in cancer cells-metastases suppressor factors as change agents. Nucleic Acids Res 2014;42:764-773.

61. Fan Z, Beresford PJ, Oh DY, et al. Tumor suppressor NM23-H1 is a granzyme A-activated DNase during CTL-mediated apoptosis, and the nucleosome assembly protein SET is its inhibitor. Cell 2003;112:659-672.
62. Zheng $L$, Roeder RG, Luo YS. Phase activation of the histone $H 2 B$ promoter by OCA-S, a coactivator complex that contains GAPDH as a key component. Cell 2003;114:255-266.

63. Michelotti EF, Sanford S, Freije JMP, et al. Nm23/PuF does not directly stimulate transcription through the $\mathrm{CT}$ element in Vivo. J Biol Chem 1997;272:22526-22530.

64. Chae S-K, Lee N-S, Lee K-J, et al. Transactivation potential of the C-terminus of human Nm23-H1. FEBS Lett 1998;423:235-238.

65. Cho S-J, Lee N-S, Jung Y-S, et al. Identification of structural domains affecting transactivation potential of Nm23. Biochem Biophys Res Commun 2001;289:738-743.

66. Cervoni L, Egistelli L, Eufemi M, et al. DNA sequences acting as binding sites for NM23/NDPK proteins in melanoma M14 cells. J Cell Biochem 2006;98:421-428. 